\title{
Cozinha de Herança: MEMórias E IDENTIDADES DE UM TESOURO COMPARTILHADO
}

\author{
Silvana Azevedo \& Fernanda Landucci Ortale*
}

RESUMO: O objetivo deste artigo é propor o conceito de Cozinha de Herança, bem como explicitar o percurso realizado para chegar a tal definição. Na primeira parte, fazemos uma breve analogia entre língua e culinária. Em seguida, percorremos os conceitos teóricos de cultura, intercultura e identidade. Na última parte, apresentamos as reflexões sobre os relatos de uma imigrante italiana que vive no Brasil e que se dedica profissionalmente à gastronomia para, finalmente, propor a definição de Cozinha de Herança.

PALAVRAS-CHAVE: memória; identidade; culinária; cozinha de herança; imigrantes.

ABSTRACT: L'obiettivo di questo articolo è proporre il concetto di Cucina Ereditaria, oltre a spiegare il percorso intrapreso per giungere a tale definizione. Nella prima parte, ci dedichiamo a una breve analogia tra lingua e cucina. In seguito presentiamo i concetti di cultura, intercultura e identità. Nell'ultima parte, presentiamo le riflessioni sulla storia di vita di un'immigrata italiana che vive in Brasile e si dedica professionalmente alla gastronomia. Infine viene presentata la definizione di Cucina Ereditaria.

PAROLE CHIAVE: memoria; identità; cucina; cucina ereditaria; immigrati.

ABSTRACT: The purpose of this paper is to define of Heritage Cuisine, as well as to explain the path taken to reach the definition. In the first part, we make a brief analogy between language and cooking. Then we go through the theoretical concepts of culture, interculture and identity. In the last part, we present reflections on the report of an Italian immigrant who lives in Brazil and professionally devotes herself to gastronomy to, finally, propose the definition Heritage Cuisine.

KEYWORDS: memory; identity; cooking; heritage cuisine; immigrants.

* Universidade de São Paulo (USP)

silvana.azevedo@usp.br / ortale@usp.br

DOI: http://dx.doi.org/10.11606/issn.2238-8281.v0i38p88-98 


\section{Introdução}

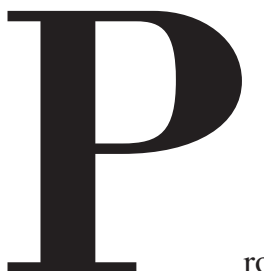

rofessor na Universidade de Bolonha, o italiano Massimo Montanari é um dos maiores especialistas em história da alimentação. Em A cozinha, lugar da identidade e das trocas, Montanari (2009) traça um paralelo entre a culinária e a língua, afirmando que exatamente como a linguagem, a cozinha expressa a cultura de quem a pratica e é depositária das tradições e das identidades de um grupo. Além da analogia dos valores simbólicos entre os dois sistemas, o autor também estabelece, no plano estrutural, a seguinte relação:

A cozinha tem sido equiparada à linguagem: como esta, possui vocábulos (os produtos, os ingredientes), que são organizados segundo regras de gramática (as receitas, que dão sentido aos ingredientes, transformando-os em alimentos), de sintaxe (o cardápio, isto é, a ordem dos pratos) e de retórica (os comportamentos de convívio). (MONTANARI, 2009, p. 11)

Essas analogias sustentam a proposta deste artigo, que consiste em tratar a cozinha, assim como a língua, como valor simbólico e expressão identitária e hereditária de um povo. Ele também nos inspira a percorrer os caminhos pavimentados pelos conceitos da língua, para só então alcançarmos o objetivo de apresentar uma contribuição teórica, propondo uma definição de Cozinha de Herança.

Nesse contexto, nos ancoramos em Língua de Herança, conceito que surgiu no Canadá, na segunda metade da década de 1970. De lá para cá, muitos foram os teóricos a tratar e definir o conceito. Neste artigo, optamos pela definição de Ortale:

Língua de herança é a língua com a qual uma pessoa possui identificação cultural e sentimento de pertencimento a determinada comunidade que a usa, seja por laços ancestrais, seja por convivência no mesmo ambiente sociocultural com falantes dessa língua. (2016, p. 27).

Essa visão ampliada do termo permite correlacioná-lo com a cozinha dos imigrantes. 
Assim como a língua, a cozinha também evidencia uma identificação cultural e a escolha de um alimento, muitas vezes, carrega o sentimento de pertencimento de uma comunidade. Heck e Belluzzo (1998) afirmam que a culinária representa identidades que não se diluem com o contato multicultural. Ao contrário, ela permanece como "marca de resistência à aculturação absoluta" e pode ser vista como um código simbólico que organiza a produção econômica e as relações. Ou seja, a prática alimentar revela o valor social, sinaliza a origem e os laços afetivos de quem a consome e traz imbricada memórias e costumes.

Neste trabalho, analisamos o testemunho de Rina De Cesaris, uma imigrante italiana que encontrou na cozinha uma forma de preservar a própria identidade e de sobreviver ao impacto cultural, à mudança de status e à distância da família. Aqui, Rina representa muitas mulheres italianas que deixaram o país de origem por amor, por melhores oportunidades ou pelo sonho de uma história com final feliz. Os registros foram gravados em áudio. Alguns trechos transcritos foram adaptados para a norma culta portuguesa, sobretudo no que diz respeito à construção das frases e à concordância verbal, com o objetivo de dar clareza às informações. As palavras ditas em italiano foram mantidas com o intuito de mostrar a presença da língua materna na fala da entrevistada. A opção por fazer adaptações nas transcrições não compromete nosso trabalho, uma vez que o foco não é a análise de aspectos linguísticos da fala da entrevistada.

Também vale mencionar que a escolha da oralidade como fonte é uma tradição na área do jornalismo e, de maneira geral, nos estudos acadêmicos que se apoiam na metodologia da história oral, que tem como foco a memória humana e a sua capacidade de relembrar o passado enquanto testemunha do vivido (MATOS e SENNA, 2011). Justamente pelo fato de a culinária ser um tema em constante transformação, consideramos relevante fazer esse registro histórico com base na vivência dos seus atores.

\section{Cultura e Intercultura}

Dize-me o que comes e te direi quem és. (Jean-Anthelme Brillat-Savarin)

Em 1825, o advogado e cozinheiro francês Brillat-Savarin lançava luz para a carga simbólica do alimento, em seu livro Physiologie du goût ${ }^{1}$. Muito antes, nos poemas homéricos a Ilíada e a Odisséia, a expressão 'comedores de pão' era usada como sinônimo de 'homens civilizados'. Afinal, preparar um alimento que não se encontra na natureza, exige um conhecimento, uma cultura. Desse modo, a cozinha ocupa o centro da passagem do mundo da natureza para o da cultura. Atala e Dória (2008) afirmam que "a cultura nasce em torno do fogo", pois através dos alimentos modificados pelo fogo, a natureza transforma-se em cultura. Portanto, comida é cultura quando produzida, quando preparada e quando consumida, porque o homem escolhe a própria comida com critérios ligados às dimensões econômicas, nutricionais e de valores (MONTANARI, 2008, p. 15-16). Ou seja, os hábitos alimentares estão intimamente ligados ao

1 Em 1995 o livro foi traduzido e publicado em português, com o título A fisiologia do Gosto. Essa obra é uma das referências na área da gastronomia. 
termo cultura, o que nos leva a focalizar algumas definições acerca desse conceito.

Primeiramente, vejamos como dois dicionários, um brasileiro e um italiano, definem o termo 'cultura'.

Cultura sf. 1. Agr. Ação, processo ou resultado de cultivar a terra, ou certa planta 2. Agr. Parte cultivada de um solo, de uma região. 3. Agr. Produto desse cultivo (cultura da soja/do cogumelo). 4. Conjunto de atividades voltadas para a criação de plantas e animais: Cultura de cítricos/de abelhas. 5. Soma das informações e conhecimentos de uma pessoa, ou de um grupo social: Era homem de grande cultura. Aquela gente lia muito, tinha cultura. 6. Conjunto de costumes predominantes num grupo ou classe social [Cf.: contracultura.] 7. Antr. Tudo o que caracteriza uma sociedade qualquer, compreendendo sua linguagem, suas técnicas, artefatos, alimentos, costumes, mitos, padrões estéticos e éticos (cultura ianomâni/neolítica). 8. Panorama de um país no que se refere ao movimento da criação e divulgação das artes, da ciência e das instituições a elas concernentes: Naquelas décadas, a cultura decaiu. 9. Antr. Conjunto dos valores intelectuais e morais, das tradições e costumes de um povo, nação, lugar ou período específico (cultura asteca/celta/ mediterrânea); civilização 10. A ação e o método de cultivar tecidos vivos, microrganismos etc. em ambiente favorável e controlado 11. P.ext. Esse ambiente, e os nutrientes que alimentam esses tecidos ou microrganismos 12. O tecido ou microrganismos assim cultivados. ${ }^{2}$

Cultura: dal latino cultura, derivato di colere, "coltivare", il termine ha acquisito, oltre all'accezione di 'coltivazione' (rispetto alla quale però prevale in italiano la forma coltura), quella metaforica di 'cura, attenzione, coltivazione di un sapere, educazione'. Della matrice etimologica, condivisa con la parola culto, il termine cultura conserva l'idea della 'trasformazione', da intendersi tanto come perfezionamento della persona quanto come intervento sulla natura e sull'ambiente sociale. In quest'ultima accezione, per influenza del tedesco Kultur, il vocabolo designa in etnologia, in sociologia e, infine, in antropologia culturale, l'insieme dei valori, dei simboli, delle concezioni, delle credenze, dei modelli di comportamento e anche delle attività materiali che caratterizzano i modi di vita dei gruppi sociali. ${ }^{3}$

Em ambos os dicionários, escolhidos aleatoriamente a título de exemplo, a relação com o cultivo e a produção de alimento se mantém, conforme já colocado na introdução desta seção do artigo. No entanto, as acepções não refletem claramente o que buscamos para dar sentido à abordagem desta pesquisa. Baccin (2012) observa que definir cultura não é tarefa fácil e, num trabalho científico, depende da área de conhecimento na qual a pesquisa está inserida.

2 Disponível em: http://www.aulete.com.br/cultura. Acesso em: 10 nov. 2019.

3 Disponível em: http://www.treccani.it/vocabolario/ricerca/cultura/. Acesso em: 10 nov. 2019. 
Nesse aspecto, embora o tema central seja a culinária, é importante lembrar que ela reflete características geográficas e históricas da localidade de origem e também expressa os valores (família, religião, arte e costumes) de quem a pratica. A abrangência do tema, torna a definição do conceito ainda mais complexa. Baccin (2012) define cultura da seguinte forma:

Cultura é um sistema adquirido e compartilhado de crenças e valores que determinam hábitos, regras, conhecimentos e tudo o que distingue o modo de vida de um grupo social. Cultura é, também, a manifestação dessas crenças, valores, hábitos, regras e conhecimentos em expressões artísticas que podem compor a "alta cultura" e a "cultura popular". E por fim, cultura é o sistema comunicativo compartilhado entre os integrantes de determinado grupo social. (p. 27) (grifos da autora)

Partindo dessa definição, entendemos que cultura é a expressão de um povo, é um conjunto de valores que determina escolhas, comportamentos, crenças e hábitos.

Há mais um dado relevante a se considerar. Conforme mencionado, este artigo tem como base de análise o relato de uma imigrante que deixou o país de origem e entrou em contato com culturas diversas. A compreensão desse movimento de desterritorialização remete ao conceito de cultura (BACCIN , 2012) como um sistema comunicativo compartilhado e à constatação de que toda comunicação é intercultural, porque coloca em contato pessoas com hábitos, crenças, valores e regras diferentes.

Isso significa que vivemos em um contexto pluricultural e estamos em constante intersecção. Ao interagirmos com diferentes grupos culturais, estamos em um contexto intercultural - 0 que nos leva à competência intercultural, que é a "capacidade de compreender e de interagir de maneira efetiva com pessoas de diferentes origens culturais" (BACCIN, 2012, p. 50).

$\mathrm{Na}$ esteira das reflexões sobre interculturalidade, Ortale (2016) lembra que adquirir competência intercultural é a "habilidade de criar para si um terceiro espaço" (p. 12). Para Crozet, Liddicoat e Lo Bianco (1999), criar o "terceiro espaço" (p. 5) não significa manter o próprio quadro de referências culturais, nem assimilar a do falante nativo, e sim, encontrar um espaço intermediário.

Transpondo essas ideias para a área da culinária, podemos dizer que não se trata de impor a cozinha tradicional do país de origem do imigrante, nem tão pouco de colocar no mesmo prato o macarrão e o arroz com feijão e banana do brasileiro, mas criar e conquistar o espaço para uma culinária intermediária. É disso que trataremos nas próximas seções a partir do relato da entrevistada.

É notório que em São Paulo, do convívio entre italianos e brasileiros, emergiu uma cozinha italiana com identidade própria, que pode ser vivenciada em alguns restaurantes italianos da cidade, mais especificamente, nas cantinas típicas paulistanas. Resultado do contato entre italianos e paulistanos, elas exibem uma ambientação própria, geralmente enfeitadas com garrafas de vinho e camisas de times de futebol penduradas no teto. No quesito comida, as receitas 
mesclam as influências dos imigrantes do sul da Itália, acrescidas dos temperos disponíveis no mercado nacional, com um toque do gosto local - características que serão tratadas com mais detalhes nas próximas seções.

\section{Cozinha e Identidade}

Outro termo que se coloca neste artigo e que tem relação direta com os aspectos culturais é o de identidade. Montanari (2009) entende que as identidades não existem sem as trocas culturais. Essa opinião encontra eco nas colocações de Trifone (2009), que define a identidade italiana como dinâmica e plural, rica e fecunda enquanto fruto de uma milenar hibridação de pessoas, línguas e culturas. Considerando a noção de identidade em si, sem a atribuição de nacionalidade, a discussão é mais ampla e a definição do conceito passa longe do estanque e está relacionada ao sujeito pós-moderno, cuja identidade "é uma festa móvel: formada e transformada continuamente." (HALL, 1997,p.11) Nesse sentido, o sujeito não tem uma identidade, mas muitas, presentes em situações diversas, que podem ser formadas por atributos até mesmo contraditórios entre si.

Ao voltar os olhos para a culinária, Baccin (2003) ressalta a importância da cozinha italiana no mundo gastronômico e afirma que ela não é apenas a somatória de diversas cozinhas regionais, mas tem-se firmado como identidade no caminhar da história. E vai além, concluindo que, ao restituir à arte da gastronomia sua própria dimensão, "as práticas alimentares e a cultura gastronômica são elementos essenciais de uma identidade italiana".

\section{A Entrevista}

Vamos passar agora à entrevista que subsidia nossas reflexões em torno do conceito de Cozinha de Herança. A entrevistada é Rina De Cesaris, uma imigrante italiana, proprietária de um restaurante em São Paulo, que vivenciou muitos momentos da gastronomia italiana na capital paulista. Seu restaurante foi inaugurado na década de 1970, antes da abertura das importações, período em que a cidade de São Paulo não tinha acesso aos ingredientes italianos com a facilidade de hoje. Também é importante ressaltar que, naquela época, havia menos informações sobre as peculiaridades da cozinha regional italiana na cidade de São Paulo. Isso favorecia a criação e adaptação de receitas ao gosto do cliente e aos produtos disponíveis no mercado. Por essa razão, essa entrevista é exemplar para ancorar e justificar o conceito de Cozinha de Herança, que é o que buscamos fazer neste artigo.

\subsection{Coisa de cinema}

Rina De Cesaris nasceu no dia 9 de agosto de 1933, em Albano Laziale, cidade da região do Lácio. Filha do cozinheiro Gioacchino De Cesaris, cresceu vendo o pai ao redor do fogão preenchendo a mesa com fartura, até que o pesadelo da guerra mudou o cenário. A rua onde 
morava foi bombardeada e a família só teve tempo de fugir com a roupa do corpo. Com 9 anos de idade, se viu morando num abrigo, com escassez e saudades das mesas fartas dos almoços de domingo. Mesmo depois do fim da guerra, não havia mais casa para onde voltar. Sua vida começou a mudar quando a beleza dos seus 17 anos a levou para as telas do cinema. A sua estreia foi em Figli non si vendono (1952), de Mario Bonnard, mesma época em que se apaixonou pelo romano Nello de Rossi, produtor executivo do filme e também ator nas produções do Cinecittà. Em sete meses se casaram e partiram para Nova Iorque. Ela se tornou costureira e o marido era gerente de um restaurante chique na cidade. A vinda para o Brasil se deu em 1973, quando o irmão de Nello morreu e deixou um restaurante para tocar. O casal não voltou mais para os Estados Unidos. Rina conta que os primeiros anos no Brasil foram difíceis, porque Nello queria voltar para os Estados Unidos. Mesmo assim, ela insistiu, penhorou algumas joias e com o dinheiro abriram um pequeno restaurante com o nome do marido. Ele cuidava do salão e Rina foi para a cozinha.

Tornar-se cozinheira foi determinante para os desdobramentos na vida de Rina. Vale mencionar Montanari (2008), que aponta a cozinha como um elemento decisivo da identidade humana e como um dos mais eficazes instrumentos para comunicá-la. “Talvez ela seja o primeiro modo de entrar em contato com culturas diversas, já que consumir o alimento alheio parece mais fácil do que decodificar a língua." (MONTANARI, 2008, p. 11)

Vejamos, a seguir, um primeiro trecho da entrevista:

Entrevistadora - Como a senhora idealizou o cardápio?

Rina - Eu não era uma dona de restaurante. Era de família. Eu fiz só prato que sabia fazer na minha família.

Entrevistadora - O que a senhora servia?

Rina - Spaghetti alla carbonara, amatriciana, saltimbocca, tutto prato romano. Tutto che mio pai fazia.

Entrevistadora - Um dos pratos mais famosos do restaurante é o gnocchi Rina. Como a senhora inventou?

Rina-É de família. Fiz. É sucesso. Simples, muito simples. Ricota, espinafre, parmesão. Não tem trigo.

Entrevistadora - Então é uma receita de família? Não se encontra em restaurantes de Roma?

Rina - É de família. Esse tipo que eu faço não encontra em restaurante. Essa é uma receita de casa, que meu mais fazia. Ele era muito bom na cozinha. 
O "gnocchi Rina" consiste em uma mistura de ricota e espinafre modelado em esferas grandes e gratinado ao forno com molho de tomate.

A identidade da culinária servida nas cantinas paulistanas carrega essa conotação de comida caseira que a dona Rina cita. Em geral, esse tipo de instituição nasceu de maneira informal na cidade de São Paulo e tinha, em sua maioria, a cozinha conduzida pela matriarca que reproduzia os pratos que alimentavam sua própria família. No entanto, há autores que enxergam sob outro prisma. Espejo (1996) entende que a cozinha das cantinas pode ser considerada uma cozinha paulistana por ter transformado substancialmente a culinária proveniente da Itália. Dória (2006) define as cantinas como "instituições genuinamente paulistanas de restauração". Vejamos como essa identidade de cozinha se consolidou ao longo dos anos na cidade de São Paulo, ainda com base em um segundo extrato da entrevista da senhora Rina.

(2)

Entrevistadora - Qual é o prato mais vendido no seu restaurante?

Rina - Parmegiana sai adoidado. A gente serve com purê e arroz. In Roma não existe bife à parmegiana. É outra coisa. É mais milanesa com molho e parmesão. Aqui coloco muçarela, perche é estilo do Brasil, né? Parmegiana lá na Itália é feito com vitela. Aqui eu faço com filé-mignon. Naquela época não tinha vitela aqui no Brasil. Tudo tive que adaptar.

Entrevistadora - Como foi a aceitação quando a senhora fez o carbonara, que leva ovo cru? As pessoas gostaram?

Rina - Gostaram. Até ganhou um prêmio. Eu coloco um pouquinho de creme de leite. Onde nasceu o carbonara, no Campo dei Fiori, não usam creme de leite, faz na panela grande onde já fritaram a pancetta. Na panela quente ainda, já com a massa dentro, jogam ovo e deixa cozinhar junto. Depois servem com pecorino romano. Na época non esisteva pecorino. Tanto che io comecei a fazer com parmesão. Acostumaram tanto que se faço com pecorino falam, non, non gosto. Mas na Itália, em casa, a gente também misturava parmesão e pecorino.

Percebe-se no relato de Rina a presença de flashes do passado longínquo vivido na Itália, mesmo sem que a pergunta induza a esse resgate. Além das memórias de família, Rina também faz questão de pontuar o conhecimento da culinária do seu país ao trazer referências de receitas clássicas, em cotejo com as versões servidas no seu restaurante. Da lista de receitas de família, citadas oralmente no início das operações do estabelecimento, hoje o cardápio do restaurante Nello's também contempla pratos que simbolizam a cozinha italiana fora da Itália. Um deles é o mencionado filé à parmegiana, carne bovina empanada com farinha de trigo e ovos, coberto por 
molho de tomate, muçarela e queijo parmesão gratinado, composição que não encontra eco nos dicionários de língua italiana consultados para esta pesquisa. Gotti (2011), por sua vez, define o termo parmigiana como uma preparação à base de berinjela ou abobrinha.

Tomando como exemplo o cardápio do Nello's, podemos concluir que o cardápio das cantinas italianas da cidade de São Paulo encontrou, na escassez de produtos específicos e nas relações interculturais entre Itália e Brasil, o seu espaço - o terceiro espaço. O contato com o outro permite não apenas avaliar a própria cultura e identidade, mas também criar a própria diversidade. Conservadoras, mas nada estáticas, as tradições alimentares são sensíveis às mudanças, limitações e influências externas. Portanto, a tradição é fruto de uma série de inovações e adaptações provocadas na cultura que as acolheu (MONTANARI, 2009, p. 12). Isso significa que a tradição um dia foi inovação.

\section{A Cozinha de Herança}

Após uma exaustiva pesquisa, não apenas bibliográfica, em diferentes âmbitos, constatamos que o conceito Cozinha de Herança ainda não foi definido. Há expressões que parecem semelhantes, mas não contemplam as múltiplas dimensões do que compreendemos por Cozinha de Herança. O mais próximo é 'comfort food', definido pelo Oxford English Dictionary como alimento que conforta ou ampara, qualquer alimento (frequentemente com um alto teor de açúcar ou carboidratos) que está associado com a infância ou a comida caseira ${ }^{4}$. Os autores Atala e Dória (2008) também apresentam a relação entre comida e sentimentos ao discorrerem sobre o que chamam de 'cozinha afetiva': aquela associada à memória e ao sabor da infância, aquela em que o toque afetivo não poderá ser substituído por nenhuma técnica e cuja continuidade depende da vigilância familiar de cada um de nós.

Ambos os termos - comfort food e cozinha afetiva - possuem uma menção direta à relação entre comida e história familiar, que consideramos relevante quando se trata de herança cultural. No entanto, em nossa opinião, um aspecto importante a ser incluído na definição de Cozinha de Herança é a transmissão das receitas entre membros de uma comunidade, a possibilidade de uma receita se tornar herança e se manter viva não apenas dentro do núcleo familiar em que originalmente esteve presente.

Nesse sentido, o testemunho de Rina De Cesaris se revela um registro importante e representa um exemplo valioso para ancorar o nosso conceito de Cozinha de Herança. Tomando por base o prato de maior sucesso no restaurante Nello's, vale lembrar que o "gnocchi Rina" carrega a simbologia de uma memória afetiva, de um prato servido em família, que não faz parte do elenco de receitas clássicas da Itália. Mas em São Paulo, ao ser preparado em um restaurante, por uma imigrante italiana, o prato passa a carregar a identidade de uma cozinha típica italiana.

Portanto, com base no conceito ampliado de língua de herança, proposto por Ortale (2016), nas reflexões sobre comfort food, comida afetiva e ainda, sobre o papel da culinária na história

4 Comfort food is a food that comforts or affords solace; hence, any food (frequently with a high sugar or carbohydrate content) that is associate with childhood or home cooking. 
de Rina De Cesaris, propomos a seguinte definição para o conceito de Cozinha de Herança:

Cozinha de Herança é aquela que desperta, em quem a prepara ou consome, memórias de um passado caro que se deseja preservar. Está relacionada a receitas e histórias carregadas de afetividade; é transmitida e compartilhada entre gerações de uma mesma família ou no contato entre membros pertencentes a uma ou mais comunidades.

\section{Considerações Finais}

As narrativas da imigrante italiana Rina De Cesaris trouxeram evidências de que a cozinha dos imigrantes tem um papel social-emocional e foi fundamental para a construção da identidade do imigrante italiano. A partir da breve contextualização histórica, política e social que permeia a trajetória de vida da entrevistada, pudemos discorrer e analisar as suas escolhas no que tange à comida servida em seu restaurante. Ficou evidente que Rina não imaginava que as memórias de criança conduziriam a sua vida adulta em torno do fogão. Nora (1993) afirma que a memória é um fenômeno atual, um elo vivido no eterno presente. O relato passeia por tempos antigos, da sua época de menina, e segue por um passado mais presente, como a lembrança espantosa de ver o paulistano pedir uma porção de arroz para despejar sobre a pizza de muçarela e citar a resistência dos clientes ao se depararem com pequenas alterações nos pratos já consagrados da casa - ainda que em prol de um certo resgate à tradicional cozinha italiana.

Conforme afirma Montanari (2009), a comida auxilia na intermediação entre culturas diferentes, abrindo os sistemas culinários a todas as formas de invenções e cruzamentos. Essas dimensões levaram-nos a compreender o conceito de "terceiro espaço" (CROZET, LIDDICOAT e LO BIANCO, 1999, p. 5) como base não apenas para conceituar Língua de Herança (ORTALE, 2016), mas também, Cozinha de Herança. Da relação intercultural entre italianos e paulistanos, surgiu uma cozinha particular, baseada em receitas de famílias estrangeiras, preparadas com ingredientes nacionais e algumas pitadas do gosto local.

Sobre a proposta do conceito Cozinha de Herança, verificamos que a expressão termo ainda não havia sido cunhada, nem pensada da forma ampla como proposto aqui. No entanto, entendemos que a Cozinha de Herança tem um papel muito importante na nossa sociedade, pois, além de nutrir o corpo, alimenta a alma, perpetua memórias, representa um elo com os antepassados e revitaliza identidades culturais de determinado(s) grupo(s). Isso justifica a necessidade de termos esse conceito explicitado e definido no âmbito dos estudos sobre identidade, interculturalidade e gastronomia. 


\section{Referências}

ATALA, A.; DÓRIA, C. A. Com unhas, dentes \& cuca-prática culinária e papo-cabeça ao alcance de todos. São Paulo: Editora Senac, 2008.

BACCIN, P. G. Terminologia alimentar italiana e a influenciada pelo italiano na cidade de São Paulo: um modelo de glossário. 2003. Tese (doutorado em Letras). Faculdade de Filosofia, Letras e Ciências Humanas, Universidade de São Paulo, São Paulo, 2003.

BACCIN, P. G. O dicionário bilíngue para aprendizes: uma ponte entre duas culturas. 2012. Tese (livre-docência) - Faculdade de Filosofia, Letras e Ciências Humanas, Universidade de São Paulo, São Paulo, 2012.

BRILLAT-SAVARIN, J. A fisiologia do gosto. São Paulo: Companhia das Letras, 2015.

DÓRIA, C. A. Estrelas no céu da boca - escritos sobre culinária e gastronomia. São Paulo: Senac, 2006.

ESPEJO, A.V. Cozinha cantineira. São Paulo: Editora Hamburg, 1996.

GOTTI, M.G. Grande enciclopedia illustrata della gastronomia. Milano: Mondadori, 2011.

HECK, M.; BELLUZZO, R. Cozinha dos imigrantes - memórias \& receitas. São Paulo: Editora DBA Melhoramentos, 1998.

LO BIANCO, J.; LIDDICOAT, A.; CROZET, C. Striving for the third place: intercultural competence through Language Education. Melbourne: Language Australia Melbourn, 1999.

MAGGIO, G.; ORTALE, F.L.; BACCIN, P.G. Identidade e bilinguismo em contexto de núcleo familiar de imigrantes italianos. Revista Italianística, v. XXX, 2015, p. 146-163.

MONTANARI, M. Comida como cultura. São Paulo: Editora Senac, 2008.

MONTANARI, M. O mundo na cozinha - história, identidade, trocas. São Paulo: Editora Senac, 2009.

NORA, P. Entre memória e história: a problemática dos lugares. Projeto História. São Paulo: PUC, n. 10, dez. 1993, p. 7-28.

ORTALE, F. L. A formação de uma professora de italiano como língua de herança: o pós-método como caminho para uma prática docente de autoria. 2016. Tese (livre-docência) - Faculdade de Filosofia, Letras e Ciências Humanas, Universidade de São Paulo, São Paulo, 2016.

TRIFONE, P. Lingua e identità - una storia sociale dell'italiano. Roma: Carocci Editore, 2009.

Recebido em: 13/12/2019

Aprovado em: 28/12/2019 